\title{
The Anthropocene Commons - A New Paradigm of Scale Variance: Commons Frameworks and Climate Change Theory Parsa Aghel ${ }^{*}$, Political Science and Economics
}

\begin{abstract}
The term Anthropocene, denoting the era where human activity is the greatest influence on the environment and climate, marks a new era of climate change theory and understanding. This paper, though, looks at existing promising works surrounding the Anthropocene and argues that the dialogue lacks holistic conceptions of agency and spatial and temporal scale variance in order to fully grasp its complexity. Agency refers to the flawed understanding of the Anthropocene as simply human without consideration for other assemblages, which denotes the other stakeholders apart from humans. Temporal scale refers to the need for a varied consideration of time and the creation of assemblages. Spatial scale refers to the different levels of interaction (national, international, socioeconomic. This understanding of scales, or scale variance, relies on Derek Woods' theory that multiple scalar levels are necessary to encapsulate the Anthropocene. This paper will approach scale variance by constructing the Anthropocene Commons model. The model, based its theoretical framework on Garrett Hardin's Tragedy of the Commons on resource, will utilize the three levels of scale absent in other scholarship. The paper will examine other models used to address climate change and discuss their lack of the necessary scope and holistic framework and how their prescriptions for addressing climate catastrophe fall short. Using scale variance in the Anthropocene commons, then, will seek to correct it and offer a standardized but flexible framework to better address the ongoing and impending crisis.
\end{abstract}

\section{INTRODUCTION}

Climate change threatens not only humans, but our entire ecosystem and the many different stakeholders within it. Choosing a scope, then, when discussing climate change or the environment in general is a difficult task. Seeking to both examine current models and frameworks and ultimately propose a new one, this paper begins by looking at Garrett Hardin's Tragedy of the Commons. A paper published in the mid-twentieth century, its discussion of resource preservation and humanity's role in it has served as inspiration for many frameworks 
that seek to encapsulate the environment and climate change. However, the scholarship lacks scale variance, a term coined by Derek Woods that denotes the different lenses with which one analyzes different environmental issues. Linear scale, for example, refers to a dialogue that is restricted to just one scale. After examining Garrett Hardin's commons, this paper looks at other scholarly uses of the commons and examines how spatial, temporal, and agency scale variance, defined earlier, are necessary to creating a holistic approach to the Anthropocene given the commons' shortcomings. As a result, the paper extracts the value of the commons, which is its theoretical ability to focus on human behavioral changes-a facet of the commons that the paper will show is crucial to fighting climate change. From there, the paper will use the constructed model and apply it to scholarship on different climate catastrophes and environmental structures, examining how the Anthropocene Commons can foster more inclusive dialogue than the current human-centric approach, and how that leads to better policy outcomes. This culminates in the model's application to climate change. Looking at the 2018 United Nations' report on future climate change, the paper will apply scale variance critiques and suggest how the Anthropocene Commons' use of scale variance is necessary to fundamentally change the way humanity approaches the environment.

\section{INTRODUCING AND EVALUATING THE TRAGEDY OF THE COMMONS}

The subject of the Anthropocene can be framed through Garrett Hardin's Tragedy of the Commons. Through his concept of the commons, Hardin begins by framing ecological preservation. Due to Earth's limited resources, he conceives of a pastoral common ground, the commons, rich with resources, foreshadowing a moment when overpopulation leads to a "tragedy" where "freedom in a commons brings ruin to all" (Hardin, 1244). He argues that in the postindustrial era, humans not only exploit the commons and deplete it of its resources, but they pollute it as well. Hardin then arrives at the crux of his argument, claiming that government can solve this issue by creating private property and "coercive laws" (Hardin, 1245). Establishing private property and laws, a neoclassical approach, is a mechanism that he believes best manipulates human behavior to fulfill a certain public necessity - in this case, preservation. Accordingly, he predicates this proposal on the notion that "the optimum population is... less than the maximum" (Hardin, 1244). However, population cannot be decreased, so he instead turns to inducing behavior changes. Though Hardin's commons problem regards overpopulation, it parallels climate change theory dialogue as they both revolve around resource consumption and depletion. Indeed, climate change, too, is exacerbated by population, but the core mechanism of resource consumption and depletion is central to its dialogue. A common example is coral reef destruction. Coral reefs are essential to maintain many biomes and ecological chains that humans benefit from, but human exploitation of resources depletes coral reefs and subsequently exacerbates climate change (USDC). Just as Hardin's commons can be reduced to overpopulation, the same can be done with coral reefs: the needs of a growing population have led to increased pollution. But population is, for good reason, not a flexible mechanism. To address climate change, one must address human behavior. Thus, in the same way that Hardin calls for "coercive laws," legislators create regulations on pollution and ocean exploitation to protect the reefs. The commons as an abstract land with resources and stakeholders that use them thus becomes a 
framework for resource pollution and consumption and prevention. As this paper will later look to apply the Commons to climate change, it is essential to understand their common denominator: solving the issue of resource scarcity requires a catalyst to modify human behavior.

However, Hardin's framework of the commons and the need for regulation is imperfect, as his theoretical prescriptions do not align with the reality of social hierarchy. One can see such issues when applying Derek Woods' concept of scale variance. The flaw is visible when examining Hardin's strikingly radical stance on free will and the role of the state with regards to population; he finds that "mutual coercion" of citizens by the government can be a mechanism to reduce the damage done to the common resources (Hardin, 1247). Woods would rebuke Hardin's assertion by looking at how his argument collapses at the society level scale when social stratification is considered. Hardin fails to acknowledge class differences and how they would affect his solution; advocating for coercion in societies with oppressive social structures would result in the government disproportionately exploiting the poor with the rich reaping the rewards. Even today, environmental regulations in the United States are far less restrictive in lower income areas. Looking at 30 hazardous waste sites, researchers at the University of Michigan and Montana found that regulations on waste did not ultimately deter behavior, but instead incentivized polluters to place their waste sites in less affluent areas (Erickson). Working at the scale of "man's population problems" for the entirety of the paper allows Hardin to articulate a capitalist-driven solution to pollution but compromises his ability to discuss the nuanced effects of introducing a theoretical constraint to a hierarchical dominated society.

In Derek Woods' paper, "Scale Critique for the Anthropocene," he highlights elements of Anthropocene dialogue that is "linear" in scale, arguing that much scholarship on the subject fails to consider a holistic perspective, opting instead to focus on a singular level or scale. One issue of dialogue he notes is that "effects of human action at the scale of global population become a collective subject figured as an individual..." (Woods, 5). Applied to Hardin's commons, this use of scale generalizes the classes of human behavior, as he fails to consider that regulations affect individuals differently based on their social class, race, and more. The scalar issue, then, ignores true polluters who would benefit from Hardin's theory. As he considers humans as a generalized entity, lacking acknowledgement of class disparities makes his analysis incomplete and linear in scope. The linearity of Hardin's commons highlights the need for scale variance to address resource issues and ultimately climate change; different stakeholders cannot be generalized without serious ramifications to solutions and regulations. Woods agrees, writing that "scale variance [is the rule...to understanding climate change" (Woods, 4). Hardin's flaws, then, become an issue of spatial scale; analyzing government regulation at the national level cannot simply address a general 'human' behavior. Instead, it must operate on individual, local, national, and global scales, for example, to even attempt to encapsulate its full effect and utility. As such, Hardin offers a compelling solution but is limited by a singular scale for the entirety of his proposal.

Looking at Mark Giordano's 2003 revisioning of Hardin's work highlights how lacking spatial scale within the commons misrepresents the Anthropocene. Straying from Hardin's linear analysis of "mutual coercion," Giordano asserts that "the nature of the commons problem for any particular resource depends in part on the scale at which it is assessed" (Giordano, 365). In 
tandem with Derek Woods' framework for holistic representation, Giordano's examination of the commons with regards to the Pacific Salmon Treaty highlights the need for scale variation. The treaty, which defines the responsibilities and rights of each stakeholder regarding salmon management, parallels the objectives of the government regulation that Hardin discusses to influence human behavior, as they both attempt to mandate certain acts to protect a public good. Despite these parallels between Hardin's and Giordano's work, Giordano begins to consider scale as he finds that the mandate led to further debate on how each domestic "commons" interacts with the Salmon Treaty. The flaw of the treaty's framework was its focus around international issues rather than domestic. Indeed, while regulations operate at a national scale, allocation impacts individuals and smaller scales of groups - commons dialogue must address all scales to fully encapsulate the effects of the treaty. Thus, Giordano's discussion of the treaty fails to eclipse Hardin's linear flaws; he, too, operates at a generalized scale that limits his commentary. Giordano's attempt to consider scale by choosing an international scale is insufficient. The issue is not picking the right scale; instead, it is simultaneously representing all scales in the discussion of the commons.

The Pacific Salmon treaty clearly demonstrates this need for spatial scale variance. Considering this particular resource dilemma demonstrates that privatizing and defining property rights within communities leads to heterogeneous effects. These rights, then, must consider various "sociopolitical scale[s]s if its effects are to be fully encapsulated (Giordano, 367). On a large national scale, exclusion of access becomes the primary concern of resource distribution as they are currently public goods, while scaling down to the household requires additional consideration of interpersonal relations as "access and use are limited to a defined set of individuals" (Giordano, 367). Without one scale or the other, one's understanding of the issues within this particular commons issue would be incomplete; this understanding of scalar perspectives becomes essential in framing a new "commons." As the paper will show, climate change theory requires a model that can represent multiple tiered issues. Thus, the commons requires spatial scale to properly represent the Anthropocene.

\section{AGENCY AND TEMPORAL SCALE IN THE COMMONS}

Both Giordano and Hardin's commons highlight the need for agency scale to be considered within the commons. As mentioned previously, Hardin's prediction of the tragedy within the commons is bleak; he makes the conclusion that "the optimum population is...less than the maximum" (Hardin, 1244). His argument is valid as he acknowledges the necessity of action, but his entire discussion places humans at the center of agency throughout the paper. The implications of anthropocentric arguments are severe. The Pacific Salmon Treaty from Giordano's work functions as an example of this; working at the international scale not only lacks acknowledgement of smaller communities, but it also fails to discuss other species and assemblages that are dependent on the river's current ecosystem. Hardin's work is guilty of the same human-centric argument. He predicates his discussion on the "United Nations' decision that "the family [is] the natural and fundamental unit of society" (1246), reaffirming that discussion of the commons and resource consumption is solely human-based. As a result, his discussion of 
the Anthropocene falls into the common trap of placing human patterns and the nuclear family in the foreground of a much broader issue of resource depletion in the entire ecosystem.

Indeed, while Hardin is correct in that human actions are primary mechanism of change in the Anthropocene, the consideration of stakeholders within the commons should be beyond humans. Different levels of scale further the discussion beyond Hardin's work, showing that "terraformers are also non-humans such as cows, genres, oil computers...the oil industry...and corn cultivation." (Woods 8). Imbued within Hardin's depiction of overpopulation is simply an analysis of human action that fails to properly represent the issue of the commons. However, many defend Hardin's lack of temporality by pointing out the fact that Hardin's piece was written in the 1950s, the Cold War era when American families were the forefront of legislation and representation. Though that may have played into Hardin's analysis and focus on the relationship between government and citizens, looking at commons representations a half-century later tells the same story, suggesting that it may be a systemic issue of dialogue.

Agency and temporal scale are intertwined; time has introduced new non-human stakeholders, or terraformers, into the commons, and an approach to agency scale must account for that instead of solely considering humans. Indeed, Derek Woods articulates, "we are no longer able to think history as exclusively human, for the very reason that we are in the Anthropocene" (Woods, 8). As Anthropocene logic highlights the fact that humans have a direct impact on the ecological landscape, their introduction of new "terraformers" within assemblage theory, which denotes the evolution of human and world activity, means that what needs to be considered within the commons goes beyond humans. Scale variance of time, or temporality, is thus necessary to be able to holistically account for such a drastic change in the commons. This is essential as this paper is proposing the application of the commons to climate change. Like the commons, current discussion of climate change inevitably requires considering human and government action, but as climate theorists would argue, that is only one scale from which to view the "tragedy of the commons". It is essential, then, to consider how Hardin's analysis of human agency within the commons is problematic. He predicates his paper on theories of Smith's rational individual as he writes, "decisions reached individually will, be the best decisions for an entire society" (Hardin, 1244). Such a statement becomes problematic as it assumes humans are entitled to make changes on behalf of society, or as Woods would put it, it regards humans as the "subject of liberalism and consumer-cum-geoengineer, capable of customizing the Earth" (Woods, 5). Hardin runs into the complex nature of writing about the Anthropocene as he fails to acknowledge its implications that our species history is not solely limited to humans. Hardin's linear scale throughout the essay prevents him from escaping this issue as variance of the lens "avoids assimilating the subject of the Anthropocene under the universal sign of species" (Woods, 7) and allows for multiple considerations of the effects of human agency in our ecological climate.

Mark Giordano's work, though it points out the issues of spatial scale with Hardin's commons, lacks proper scale variation of temporality and agency to represent the Anthropocene. As he describes issues with selecting the right spatial scale with commons issues, he focuses solely on human interaction within nature, rather than with nature. Giordano's work surrounding pollution only considers international consequences rather than considering nature itself as a 
victimized terraformer. He writes, "Americans tended to pollute their downstream neighbors, whereas Canadians 'tend[ed] to pollute themselves," creating an "economics" issue (Giordano, 371). To engage only with the human and economic sides of pollution within the commons limits Giordano's discussion, as he does not acknowledge the various other terraformers and stakeholders, like biodiversity and the water ecosystem, within the varying pollution patterns of nations. Thus, Giordano comes short in his assertion as he lacks acknowledgment that the discussion of the Anthropocene is not simply about scale among humans, but rather a holistic consideration of all terraformers. Without addressing the shift and growth of other terraformers in his scenarios, he lacks the temporal consideration of other "assemblages" (Woods) that would add another layer on top of his assertion. His analysis focuses solely on "sociopolitical scale" (Giordano 365), rather than extending the boundaries of his commons to the growth of both species and other factors as well. Regardless of the time period, both Giordano and Hardin's analysis revolve around an anthropocentric framework of human behavior, showing how the commons still has not begun to account for the growth of its boundaries for all of assemblage theory. The commons necessitates consideration of temporality and agency, acknowledging changes that occur within the ecological landscape and the terraformers within the space. The implications of not doing so are disastrous; considering environmental reform without considering the environment is counterproductive to the original intent of altering the status quo.

\section{THE UTILITY OF THE COMMONS}

Despite these issues, the commons' consideration of human behavior highlights its foundational position within climate change theory, as both have traditionally attempted to alter human activity. Matthew MacLellan writes in his paper, "The Tragedy of Limitless Growth: Reinterpreting the Tragedy of the Commons for a Century of Climate Change," that the commons becomes a more effective model when it considers changing human behavior rather than simply arguing for governmental regulation, as climate change cannot be fully addressed by the latter (MacLellan, 42). Precisely, Hardin's framework of government regulation to solve the world's issues of resource depletion is not particularly insightful because many political obstacles have inhibited attempts to decrease global carbon emissions (MacLellan, 43). Indeed, this reading of his work, which has become the framework for other commons interpretations, does not account for the need for scale variance in order to represent the resources that are corrupted when subjected to market economics (MacLellan, 42). Hardin and Giordano's proposals thus become far more ineffective; proposals based in "capitalist imperative for limitless growth" consider only human agency, lack consideration for the spatial dimensions of their proposals, and do not account for the transgenerational changes in the ecological landscape. The question then becomes, why is the commons necessary? There must be utility to the model, as Garrett Hardin's introduction to consumption and conservation of resources in 1958 had major political implications and impacts, leading to the foundation of the World Bank and IMF policies (MacLellan, 42).

The utility, then, is in Hardin's paradigm construction, which builds a model based on the scarcity of resources due to human behavioral patterns and the need to conserve them. Reading 
the commons without the political restriction and privatization that created spatial, temporal, and agency issues reframes environmental degradation not as an issue of property but instead a problem of growth, meaning that changing human patterns is the key to avoiding the tragedy of the commons, not property allocation. Instead, reading the commons as a model of growth accounts for the scalar needs of "a truly global environment crisis that doesn't respect political borders or property lines," allowing for responses beyond "scientific marvel alone" (MacLellan, 43). Without an explicit response rooted in government action, Hardin and Giordano's commons read as a "tragic" mode, meaning that they highlight the inevitability of the "tragedy of the commons" if the patterns of "rational" human activity continue as they do (MacLellan, 52). The theory of the commons, an abstracted model of a space damaged by exploitation, is ultimately a tool for imagining how human action has led to the impending threat of resource depletion, but even beyond MacLellan's reading, how human species are one of many terraformers that must be considered when responding to such a layered threat. When adding spatial, temporal, and agency scale to the commons, it becomes a model beyond government action, calling instead for fundamental changes in humanity's values or conceptions of morality (MacLellan, 57). One can see the symbiotic relationship beginning to form between the commons and climate change theory; climate change theory needs a mechanism to represent responses that are more complex than simple market and regulation-based approaches, while the commons would become a more accurate model if it applied scale variance to become a more holistic representation of the Anthropocene.

\section{THE ANTHROPOCENE COMMONS: A NEW COMMONS FRAMEWORK}

Having established the theory of the commons as the foundation of the Anthropocene's dialogue, this paper will now begin to formulate its design. Timothy Clark's concept of three scales provides an applied framework for the commons to build on. In "Climate Change, Scale, and Literary Criticism: A Conversation," Michael Clarke and Faye Halpern discuss the utility of Timothy Clark's derangements of scale, specifically with the variance between the individual, national, and hypothetical scale. As they discuss certain pieces of literature that engage in dialogue with climate change, the commons and the pieces form a parallel: both require scale variance in order to accurately represent the Anthropocene and the commons. This paper has identified three categories of scale as issues within the commons: temporal, spatial, and agency. The issue of spatial scale aligns with Clark's distinction between the individual and national, demonstrated through Giordano and Hardin's shortcomings when lacking spatial scale variation. Hardin lacks discussion of how developments at the national level affect the sociopolitical levels, while the combination of national and individual in Clark's work allows for discussion of the "immediate circle of family and acquaintances" and their "plac[e]...in the cultural context" (Clark, 5). Thus, creating a holistic representation through the commons could be achieved by creating a distinction between scales of individual and the national, similar to Clark.

Furthermore, Michael Clarke and Halpern articulate that "global warming requires us to change the way that we think about human agency," meaning that the Anthropocene is beyond just human discussion, similar to Woods' assemblage theory that can be used to point out key 
flaws in Giordano and Hardin's commons (Clarke \& Halpern, 9). Certain dialogue surrounding action on climate change, such as Giordano's exploration of household and national policy, leads to "fantasies of agency," such as suggestions that the market or a number of regulations are sufficient to solve such a crisis, and thus limit the very purpose of discussing the Anthropocene and climate change theory (Clarke \& Halpern, 9). The commons, as Woods would agree, should not only be discussed on various scales of human interaction but also at the level of species and assemblages as well. Timothy Clark's third scale becomes useful here, as it illustrates a long-term and abstract framework that considers far more than the individual or national scales. Giordano struggled with accounting for the changes occurring to the commons in the postindustrial era and focused solely on the national and sociopolitical scales. With that, the third scale could "highlight the alarming factors that reduce human agency's impact...while simultaneously implicating it," (Clarke \& Halpern, 15) leading to a more nuanced discussion of the Anthropocene, as it begs the question: who or what must be considered in the commons other than humans? Thus Giordano and others could use the third scale to "[become] aware of the work of nonhuman players in the environmental change and of the limits of individual agency" (Clarke \& Halpern, 16). Despite the assertion made by Clark and Clarke, Faye Halpern disagrees, suggesting that Timothy Clark's first scale is a better frame as it doesn't "deny agency" (Clarke and Halpern, 5). Here, Halpern misunderstands the purpose of the varying scales; while he imagines them as mutually exclusive, they are most functional when working together simultaneously. If those discussing climate change utilized scale variance and intertwined both nuclear and hypothetical scales, it would place "human agency...on the same level as nonhuman agency" (Clarke \& Halpern, 17). Thus, from this, we can imagine a new commons interpretation better suited to represent the Anthropocene, similar to Timothy Clark's scale (Figure 1):

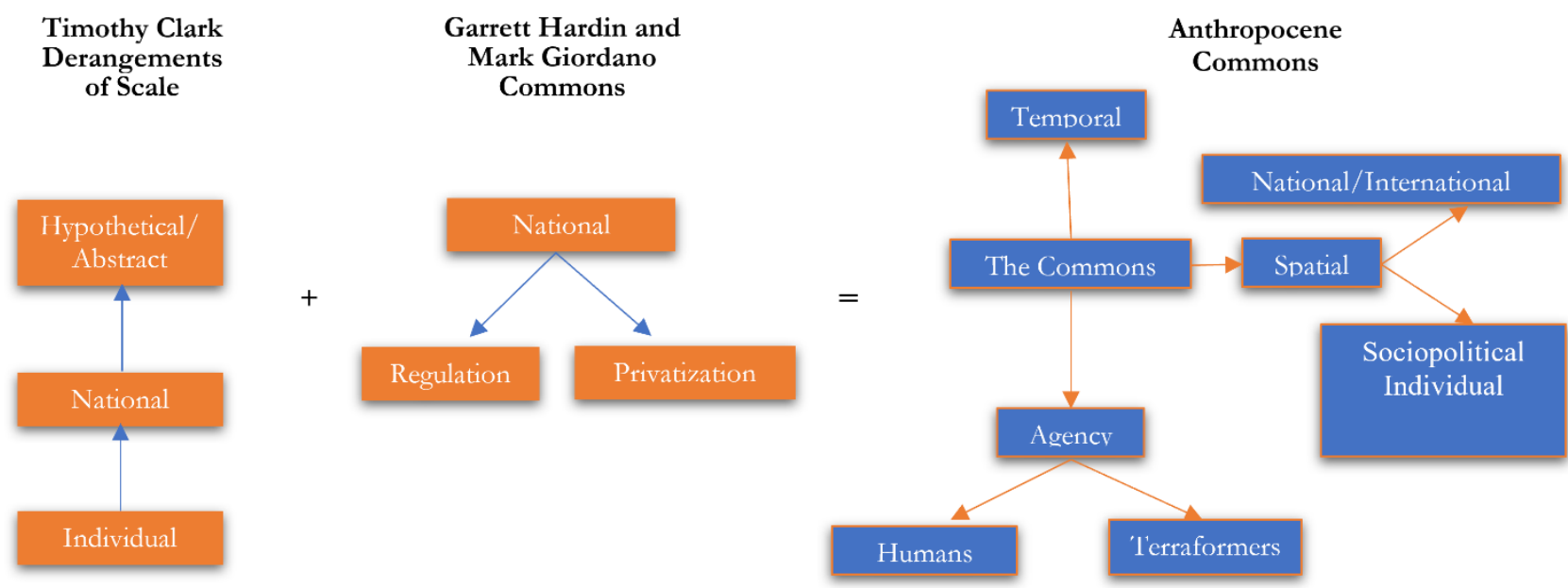

Figure 1: Clark's and Hardin and Giordano's commons scales can be reimagined into a new framework better suited to represent the Anthropocene.

The three diagrams outline the theories that have been discussed up to this point. Giordano and Hardin both operated at a national scale that only considers regulation, such as the Salmon Treaty, or privatization, like Hardin suggesting privatizing resources. Timothy Clark's 
Derangement's of Scale shows the progression of scales from the individual to the national, but also an abstracted scale that accounts for other assemblages and the introduction of new ones. The Anthropocene Commons builds on both and seeks to create a holistic representation of the Anthropocene to later apply it to climate change. It functions on the three scales discussed in the paper: spatial, temporal, and agency scale. The agency scale places humans at the same level as other terraformers. The spatial scale accounts for national levels but also considers sociopolitical and individual scales whose absence has plagued other scholarships. These three scales provide a framework for incorporating scale variance into climate change theory, as this paper will argue that the scales are precisely what is necessary to encapsulate the dialogue necessary for the subject.

\section{APPLYING THE COMMONS TO CLIMATE CHANGE THEORY}

The current discussion surrounding climate change theory highlights the need for a homogenous model of the commons in order to avoid disastrous consequences. In Shahzad Ansari's study, "Constructing a Climate Change Logic: An Institutional Perspective on the "Tragedy of the Commons," he studies how various actors within climate change discussion revolve around a "commons" logic in order to find common ground. However, as he investigates various actors engaging in climate change dialogue, they too run into the same issue of focusing mostly on the national level, lacking engagement with other levels of spatiality and agency (Ansari, 1014). Ansari finds that "eventually, a number of actors converged around a commons logic for climate change, although not all the key actors embraced this logic simultaneously and to the same extent." (Ansari, 13) Though most of the actors acknowledged the existence of a problem, there was not a standardized method or underlying logic; some organizations such as the European Union and environmental NGOs focused on the state, while G-77 focused on the community, and the Global Climate Coalition and JUSSCANNZ looked at the market (Ansari, 1022). None of the frameworks used looked beyond human stakeholders or included considerations of an ecological "logic." As a result, their work is guilty of the same flaws that Hardin and Giordano's work have, except these organizations actually work towards implementing policy. Without any scale variance, their solutions, too, lack the necessary scope. Ultimately, the various global initiatives used frameworks resembling a commons logic. However, the "transnational problems, especially those related to commons, pose formidable challenges for business, governmental, and civic leaders globally" (Ansari, 1034), meaning that the lack of a homogenous and holistic approach limited all of their initiatives.

Similar to what MacLellan pointed out, working within the "capitalist imperatives for limitless growth" by focusing on the market or national level hinders the effectiveness of policy, as current scholarship fails to consider the large threat that climate change poses beyond human agency. While this paper will point out explicit consequences of lacking scale variance, simply considering climate change dialogue as solely concerning humans, and no other terraformers like other species, parts of biomes, etc. could lead to an exacerbation of a dynamic where humans claim ownership of the land's resources. This would reify human-centric action, which is largely the cause of climate change in the first place. 
The issue of the chosen scales to view climate change can be further explored in Anthony Patt's paper, "Beyond the Tragedy of the Commons: Reframing Effective Climate Change Governance." Paralleling Ansari's observation of various forms of commons logic, he too finds that the scholarship's "problem frame[s]," meaning their framework for approaching the environment, simplified a complex issue like climate change, rendering their solutions ineffective (Patt, 2). Indeed, similar to the issues pointed out with the spatiality in Hardin's piece, imagining a "tragedy of the commons" currently points towards capitalist imperatives of restriction or privatization to limit consumption, precisely what this paper has articulated as the wrong approach towards the commons. Patt argues that regulation is the wrong approach to the commons by highlighting how regulation is not sufficient to deter crime-specifically, murder. Despite murder being a public bad, Patt argues that "we don't solve it by imposing a tax or allocating permits," but instead try to shift behavior by prohibiting it and influencing human's moral compass. The same logic applies to climate change; reducing the damage of climate change does not come by adding a new shape to the commons or "imposing a tax or allocating a limited number of permits. We prohibit it" (Patt, 2). Patt's discussion of a commons logic is clear: the model of the Anthropocene must engage in dialogue with climate change by changing human behavior.

Furthermore, the commons accommodates the future of the Anthropocene by considering evolution. One of the key errors with Hardin and Giordano was the issue of temporality, as the commons had expanded as a result of the industrial revolution, introducing new terraformers that needed to be considered. As a result, Patt highlights the influence that the commons has on the long-term direction that climate change action takes, pointing out like MacLellan that the "tragedy of the commons framing offered clear guidance in terms of the appropriate policy instruments, so too does an evolutionary framing" (Patt, 3). Furthermore, as Ansari showed, the need for standardization is necessary to prevent the same mistake that multiple initiatives made by choosing various frames that did not cooperate with each other. Climate change theory and dialogue, therefore, need not only a model to account for large temporal, agency, and spatial scale, but to also agree on the motive that most properly represents the Anthropocene: shifting human behavior to support ceasing damage to the ecological state for all terraformers. The Anthropocene commons achieves precisely this: by accounting for various spatial scales it addresses what direction and level initiatives operate at while considering the vast stakeholders being affected, and through temporal scale allows for further growth of the commons.

\section{APPLYING THE ANTHROPOCENE COMMONS TO CLIMATE CHANGE THEORY}

Within climate change theory, specific research on global warming catastrophes highlights the utility of the Anthropocene commons and the implications of not adjusting to scale variance. The paper, "Definitions of Event Magnitudes, Spatial Scales, and Goals for Climate Change Adaptation and their Importance for Innovation and Implementation" highlights the implications of research not adjusting to scale variance in order to advocate for a holistic approach to climate change. As the researchers investigated responses to a major disaster in Copenhagen, they examine different actors' conceptualizations of climate change, essentially categorizing them into levels of spatial 
scale: international, national, and regional. Their findings further support the need for a model that accounts for all levels of spatiality, as the authors describe the domains and scale as one of the "characterizing attributes of climate change adaptation" (Madsen et al., 200). Their findings agree with Ansari and Patt's works as they linear scale usage, which leads to improper Anthropocene dialogue, but Madsen's study shows the tangible effects of lacking a standardized model for all actors in a climate change dialogue. Instead of grasping the full magnitude of the event and characterizing it correctly, the study demonstrates how research on climate change in a certain commons focuses on linear scales; each of these scales, though, led to disagreeing solutions to the flood. Such errors, however, cannot be attributed to the actors themselves but rather a lack of a specific model for all of climate change research to fit into.

The argument for the Anthropocene commons can be made as the study shows that lacking a structure and dialogue that is agreed upon leads to the actors filling in blanks themselves "to match their specific project, resulting in inconsistent definitions" (Madsen et al., 198). The Anthropocene commons, furthermore, accounts for various levels of spatial scale through scale variance, allowing for a single issue to be considered on different levels of impact simultaneously instead of one exclusively.

The benefits of the Anthropocene commons are apparent when considering its application to the study. The study demonstrates how each actor selected a single spatial scale within the Copenhagen flood, ranging from the sewer system, cadaster, and the homeowners' association (Madsen et al., 200). Similar to Patt's argument, the scales of the commons and climate change discussion set the direction for initiatives, as various goals were considered by actors such as reducing cost, reducing sewage volume, and optimizing urban land use planning (Madsen et al., 200). Having a goal within a climate change disaster is not a problem; however, each actor operating in different ones makes initiatives far less effective and pose severe ramifications as they "present a possibility for conflict, which becomes visible in the implementation of climate change adaptation...and knowledge sharing...activities" (Madsen et al, 201). The notion that "there is no clear definition of climate change adaptation" (Madsen et al, 201) suggests that perhaps the flaw regarding the commons can be rectified through the scale variance, as its holistic nature would require actors to consider all levels of scale when examining an incident. Nonhuman terraformers would also be addressed, as a larger scale view of incidents like flooding would require consideration beyond human infrastructure of the ecological state. For example, in the case of the Copenhagen flooding, acknowledging other assemblages might require looking at how the use of resources for repairs might impact environments that other species use, or even if species were affected by the flood. The paper mentions damage to a wastewater treatment plant; looking at other terraformers would require seeing how other species and stakeholders are dependent on the treatment plant (Madsen et al, 198). Like mentioned previously, the Anthropocene commons bases its scale on the idea of Woods' scale variance, meaning that if applied to the Copenhagen flooding, it would allow for cohesive knowledge sharing amongst individuals but also create a more accurate presentation of the commons for action regarding climate change. 
On a much smaller scale, the Network Political Ecology framework offers a look at how the concepts of the Anthropocene commons benefit climate change theory. Birkenholtz writes in "Network Political Ecology: Method and Theory in Climate Change Vulnerability and Adaptation Research" about the need for advancements in network theories of scale to beyond what is discussed in market and regulatory dialogue. Indeed, this paper's proposal parallels the Anthropocene commons as they both seek to better the dialogue of climate change by properly representing the large scale of the Anthropocene on multiple levels. Birkenholtz crafts network political ecology in a similar fashion as he melds extensive research methods, which analyze events through patterns statistical methods, and intensive methods, which attempt to understand the patterns by looking at the events themselves through anthropological approaches. The final product becomes a method of research that considers individual events from multiple scales and holistically represents them rather than posing them as independent analysis, just as the Anthropocene commons is designed to do. Much of the research done on climate change, like the Copenhagen flooding, failed to create effective action as their research focused on scales that didn't grasp the magnitude of the changes and the impacts it had on assemblages and the ecology. What is needed is research methods that acknowledge "social structure, human agency and the environment," as these variables are precisely what the Anthropocene Commons' advocates for (Birkenholtz, 301). Scale variance provides the holistic outlook to prescribe proper solutions.

Precisely as Birkenholtz's paper articulates, solutions focusing on sewage systems like in Copenhagen or on technological marvels are ineffective because they lack consideration of other scales or stakeholders that require different solutions. The purpose of research needs to consider modifying human behavioral patterns and seeing the holistic effects of these changes on various scales rather a linear approach that considers the effect on one group at one scale. Birkenholtz illustrates how better research is being conducted in a study on groundwater irrigation in Rajasthan, an area with a "high degree of socio-ecological heterogeneity but where a particular resource use system is relatively constant” (Birkenholtz, 305). As a result of precipitation pattern changes, the case study looked at how cropping and harvesting would affect both the areas economically and socio-politically in order to avoid limiting the dialogue to one area and restricting the scope. As a result of a scale variance approach, they not only found that the precipitation changes would affect crop patterns but would also "have negative effects on gendered labor burdens and power relations," as small farmers would suffer from not receiving state resources (Birkenholtz, 308). Ultimately the authors found that having an approach that accommodated different scales led to "a better and more nuanced understanding of these processes...[and] a better position to inform policy debates" (Birkenholtz, 310). These positive conclusions have been absent in all of the other scholarship that this paper has considered. Thus, the application of network political ecology allowed for the complex issue of agrarian perturbations to be researched on all levels of the impacts, highlighting the benefits of research with holistic approaches to climate change.

As network political theory looks at socio-ecological processes on various levels of scale and successfully examines ecological perturbations, the question becomes: why is the commons necessary if network political ecology works? The commons, though based on the same principles 
of scale variance, explicitly considers temporality and agency unlike network political ecology, equipping it for the future of evolution and climate change. In the case of Rajasthan from network political ecology, the Anthropocene commons would build on the existing use of scale variance, but its study would be longer term and account for the precipitation's effect on biodiversity in the area. Lacking temporal consideration, the study failed to consider the introduction of new assemblages. While the study considered gendered labor burdens and power relations, it lacked consideration for any other form of terraformer, like species who would be affected by new policy, in the region. The Anthropocene Commons highlights how humans introduced new terraformers and impacts on the ecological state. It acknowledges the broader spectrum of "assemblage theory," meaning the dialogue is more holistic and effective by considering impacts beyond humans. Only considering human needs, of course, is precisely the cause of much of the environmental catastrophe faced today. Ultimately, network political ecology highlights the impact that holistic approaches have when applied to climate change research, opening the door for more inclusive policy and dialogue if the Anthropocene commons were to be applied to climate change theory.

Applying the Anthropocene commons to climate change theory shows the potential for more holistic dialogue to improve policy when looking at the United Nations Intergovernmental Panel on Climate Change's report on the climate developed over two years. This investigation focuses on the "Summary for Policymakers," which provides "key findings" that the panel finds relevant for initiatives. The most important feature that they begin with is the $1.5^{\circ} \mathrm{C}$ increase, which refers to the global temperature increase that causes catastrophic and irreversible climate damage, as it leads to "Climate-related risks for natural and human systems are higher for global warming of $1.5^{\circ} \mathrm{C}$ than at present, but lower than at $2^{\circ} \mathrm{C}$ " (IPCC, 5). In an entire two-page section dedicated to the results of $\mathrm{CO}_{2}$ emissions on the atmosphere, only one sentence mentions that the risks "depend on...geographic location" (IPCC, 5). "Geographic location" includes consideration for marginalized countries, cultures, species and more that require special consideration. To reduce $\mathrm{CO}_{2}$ emissions' disproportionate effects on different areas to one sentence without explaining the different effects leads to generalized and linear forms of dialogue that lessen the efficacy of solutions, just like the solutions presented in the rest of the scholarship critiqued in this paper. Indeed, scalar issues pervade the paper that is supposed to describe all of the issues to be addressed by policy.

The summary makes the same mistake that the Copenhagen flooding and Hardin's commons make: that is, operating at a spatial scale that does not include the smaller scales, such as the impoverished and other nations in far worse economic and geographic position that already suffer from the effects of global temperature increases. An average temperature that becomes the headline of every news report effectively marginalizes those who suffer the immediate consequences (because the report waits for an effect that is already happening to some) simply because the spatial scale was not varied in the discussion. For example, perhaps while the average has not reached $1.5^{\circ} \mathrm{C}$, one specific geographic area has and thus faces the environmental consequences. An average measurement, then, would not acknowledge that area until the aggregate reaches them, leading to disparate environmental effects. The Anthropocene commons 
would fit in here; the $1.5^{\circ} \mathrm{C}$ would still be a concern, but on a different scale, the UN panel would consider the fact that certain areas already require the aid that is planned for the future if the global average catches up. The threats posed to other areas currently suffering, then, would also be included in the discussion. In doing so, the dialogue would ensure that policy-makers are more aware of the need for global initiatives to avoid the threshold but understand that other areas already experience the impacts of global consumption.

The need for a better sense of not only spatial but temporal scale variance is demonstrated in a graph that the report provides (Figure 2).

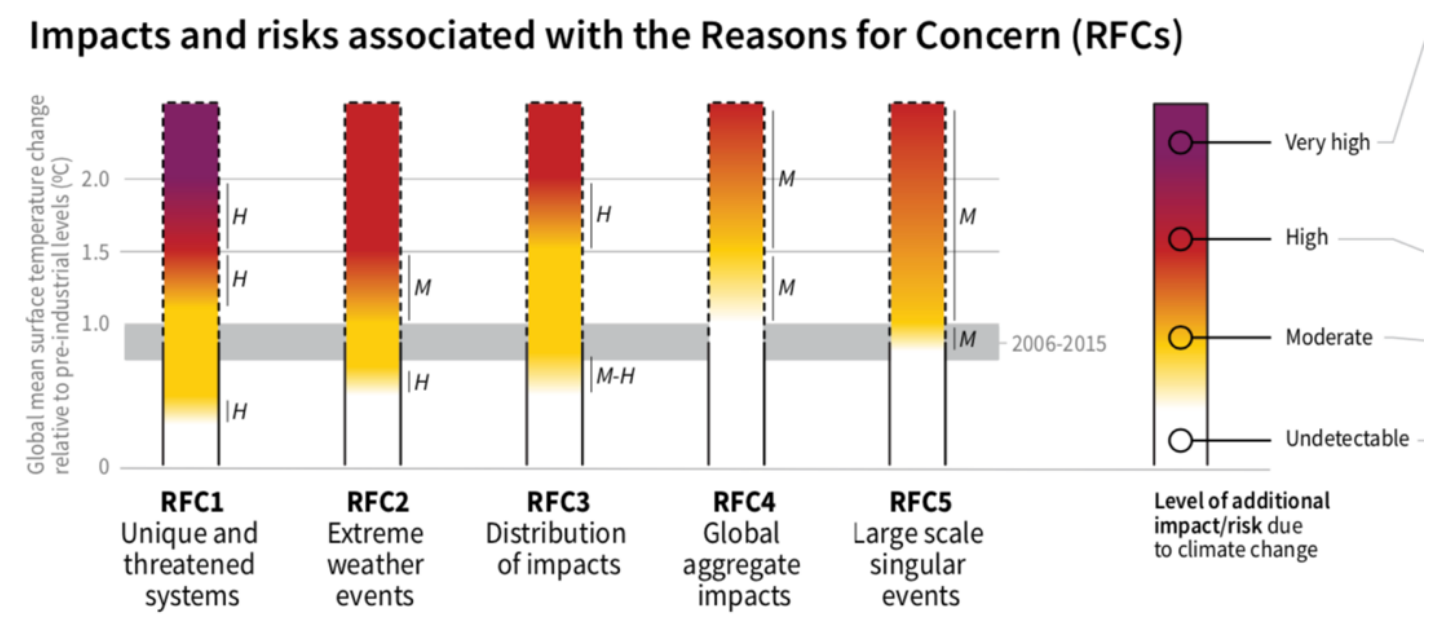

Figure 2: Graph from a report by the United Nations Intergovernmental Panel on Climate Change.

As the investigation surrounds the global catastrophe that will occur if action is not taken, the $1.5^{\circ} \mathrm{C}$ shifts the focus to imaginations of resource depletion globally and more "large scale singular events." The graph looks at different reasons for concern regarding global warming and evaluates them on a risk scale. Detailing five different impacts, only one of them examines how threatened systems already face the consequences of rising temperatures. Instead, it simply denotes that reality with a darker color among other risks. The graph not only again perpetuates the issues of spatial scale, as it lacks any discussion of the high risks in the graph associated with threatened systems, but it also suffers temporally as the graph illustrates a "risk," neglecting to acknowledge that these systems currently suffer. Choosing to describe events as risks as the $1.5^{\circ} \mathrm{C}$ threshold has not been reached improperly represents the dangers of climate change, as future and current impacts are melded into one that generalizes certain areas. This is not to say that the report intentionally makes these choices to marginalize certain populations. However, applying the values of the commons would create a more holistic narrative that acknowledges both the present impacts on areas of poor economic status but also the future global threats.

Agency scale is also an area where the report would benefit from the application of the commons. The paper's section of "indicative linkages between mitigation options and sustainable development using SDG's" discusses different sectors that initiatives can focus on to avoid the $1.5^{\circ} \mathrm{C}$ threshold. The overarching point they make is that limiting the risks of warming $1.5^{\circ} \mathrm{C}$ in terms of "sustainable development and poverty eradication" means that there needs to be 
increased investment in adaption and mitigation, policy instruments, technological innovation, and finally behavioral changes (IPCC, 21). In their actual discussion, however, the dialogue almost exclusively revolves around diversification of the "economy and energy sector" and private fund investment by institutions (IPCC, 21). Just as MacLellan points out that discussions of climate change lack scale variance as they revolve around capitalistic imperatives or technological marvel, the UN report does the same, merely paying lip service to "behavioral changes," which studies have shown is the most crucial aspect in addressing climate change.

The Anthropocene commons, if considered by this report and further discussion, would shift the focus towards the "behavior changes," as the other proposals operate only on more technology and modification. Policy and investment can do only so much; addressing climate change means changing the way humans view their role in the environment. Much of the damage incurred came from exploitation that did not acknowledge other assemblages who suffer as a result. Climate change, now, is the consequence of that. Behavior shifting means accommodating other assemblages, including the environment itself. If nature is just treated as a commodity, no form of investment can stop the continuation of its exploitation-it can just hope to slow it down. Without a focus on behavioral changes, individuals will be enabled to continue their same patterns as the burden of saving all those in assemblage theory is directed towards "multilevel governance" and "institutional investors" (IPCC, 23). This report shows incredible non-biased initiative, however, with the Anthropocene commons' spatial, temporal, and agency scale, the method would fundamentally change the way humans and policymakers evaluate climate change and humanity's role in it. Considerations for a more holistic approach and non-human-centric dialogue would capture the meso-scale depth of climate change beyond technology and the 1.5-degree Celsius threshold.

\section{CONCLUSION}

This paper began by looking at Garrett Hardin's 1958 "The Tragedy of the Commons" and examined its utility as a theoretical framework for dialogue surrounding resource conservation and ultimately climate change. However, the theory is not perfect as it, like much of the other existing scholarship, lacks scale variance, a critique that Derek Wood's applies to Anthropocene dialogue. Today, of course, the ecological state of the world has shifted, as the Anthropocene marks a time where human action has created a new group of terraformers that need to be considered beyond neoclassical regulation and privatization. This paper, then, has formulated a model that requires spatial, temporal, and agency scale variance to holistically represent the Anthropocene. Climate change theory, whether research or initiatives, suffers from the same issues, as it revolves around the economic market and human impacts only, failing to acknowledge the levels of depth that need to be considered. The Anthropocene commons seeks to bridge the gap between the two and further create a more accurate representation of climate change. This new model by no means solves climate change; however, it creates a more holistic dialogue for both research and policy to engage with. It does so by radically changing the way that humans evaluate their role within the broader world. Most of the scholarship remains in the humancentric viewing of the world; by erasing that assumption through scale variance, the Anthropocene 
Commons places the dialogue in a space where humans are just one of many different assemblages. This behavior shift is precisely how climate change must be approached. It is not an issue that technology alone can solve; human-centric dialogue allows humans to continue acting within the status quo. This paper does not solve climate change, but it seeks to provide a model that might catalyze the dialogue that can.

\section{ACKNOWLEDGMENTS}

I would like to thank my sponsoring faculty member, Professor Anita Chari, and Professor Casey Shoop, who inspired and helped me turn what was just a passionate idea into what it is now. I would not be here without your academic support. I'd also like to thank Jakob Hollenbeck, Jonathan Ely, and Aaron Lewis for being the best bouncing board, editors, and roommates during this process - even when I accidentally deleted its first draft.

\section{REFERENCES}

Ansari, Shahzad, Frank Wijen, and Barbara Gray. "Constructing a Climate Change Logic: An Institutional Perspective on the "Tragedy of the Commons"." Organization Science 24, no. 4 (2013): pp. 1014-040.

Birkenholtz, Trevor. "Network Political Ecology: Method and Theory in Climate Change Vulnerability and Adaptation Research." Progress in Human Geography 36, no. 3 (2012): pp. 295-315.

Clark, Timothy. "Telemorphosis: Theory in the Era of Climate Change, Vol. 1." Derangements of Scale1 (2012). doi:10.3998/ohp.10539563.0001.001.

Clarke, Michael T., Halpern, Faye, and Timothy Clark. "Climate Change, Scale, and Literary Criticism: A Conversation.” Ariel: a Review of International English Literature. Vol. 46 No. 3, pp. 1-22.

Erickson, J. (2016, January 19). Targeting minority, low-income neighborhoods for hazardous waste sites. Retrieved May 12, 2021, from https://news.umich.edu/targeting-minority-lowincome-neighborhoods-for-hazardous-waste-sites/

Giordano, Mark. "The Geography of the Commons: The Role of Scale and Space." Annals of the Association of American Geographers, 93(2), 2003, pp. 365-375.

Hardin, Garrett James. The Tragedy of the Commons. University of California, 2009.

IPCC, 2018: Global warming of $1.5^{\circ} \mathrm{C}$. An IPCC Special Report on the impacts of global warming of $1.5^{\circ} \mathrm{C}$ above pre-industrial levels and related global greenhouse gas emission pathways, in the context of strengthening the global response to the threat of climate change, sustainable development, and efforts to eradicate poverty [V. Masson-Delmotte, P. Zhai, H. O. Pörtner, D. Roberts, J. Skea, P.R. Shukla, A. Pirani, W. Moufouma-Okia, C. Péan, 
R. Pidcock, S. Connors, J. B. R. Matthews, Y. Chen, X. Zhou, M. I. Gomis, E. Lonnoy, T. Maycock, M. Tignor, T. Waterfield (eds.)]. In Press.

Maclellan, Matthew. "The Tragedy of Limitless Growth: Re-interpreting the Tragedy of the Commons for a Century of Climate Change." Environmental Humanities 7, no. 1 (2015): pp. 41-58.

Madsen, Andersen, Rygaard, and Mikkelsen. "Definitions of Event Magnitudes, Spatial Scales, and Goals for Climate Change Adaptation and Their Importance for Innovation and Implementation." Water Research 144 (2018): pp. 192-203.

Mertens, Mahlu and Stef Craps. "Contemporary Fiction Vs. the Challenge of Imagining the Timescale of Climate Change." Studies in the Novel, Vol. 50 No. 1. (Spring 2018) pp. 134153.

Patt, Anthony. "Beyond the Tragedy of the Commons: Reframing Effective Climate Change Governance." Energy Research \& Social Science 34 (2017): pp. 1-3.

Saintilan, Neil, Kerrylee Rogers, and Timothy J. Ralph. "Matching Research and Policy Tools to Scales of Climate-change Adaptation in the Murray-Darling, a Large Australian River Basin: A Review." Hydrobiologia 708, no. 1 (2013): pp. 97-109.

Schlager, Edella, and Elinor Ostrom. "Property-Rights Regimes and Natural Resources: A Conceptual Analysis." Land Economics68, no. 3 (1992): 249-62. doi:10.2307/3146375.

US Department of Commerce, N. (2015, March 03). How does pollution threaten coral reefs? Retrieved May 12, 2021, from https://oceanservice.noaa.gov/facts/coral-pollution.html

Woods, and Derek. "Scale Critique for the Anthropocene." The Minnesota Review, Duke University Press, 1 Nov. 2014, read.dukeupress.edu/the-minnesotareview/article/2014/83/133/48091/Scale-Critique-for-the-Anthropocene. 